\title{
chapter A Sociological Perspective $F$ on Psychiatric Epidemiology in Britain
}

\author{
David Pilgrim and Anne Rogers
}

\section{Introduction}

The relationship between psychiatry and sociology has been both 'troubled' and collaborative. ${ }^{1}$ Social psychiatry represents a reconciliation between positivist labelling in the profession (diagnoses) and social causations, as an alternative to bio-determinism. Either side of the Second World War, social psychiatry had emerged in the United States, influenced by Adolf Meyer's work, the ecological wing of the Chicago School of sociology and, subsequently, the development of the biopsychosocial model by George Engel.

In Britain, during the twentieth century 'environmentalism' or 'the social' was evident in the treatment of shellshock and in the development of therapeutic communities as well as in the emergence of attachment theory and social epidemiology. ${ }^{2}$ The last of these offered us a 'bio-social' model of common mental disorders, deleting the 'psychological' from the biopsychosocial model. ${ }^{3}$ Before looking at the ways in which this legacy influenced psychiatric research, we consider the influence of the nearby British sociological work of George Brown and his colleagues.

\section{The Social Origins of Depression}

Originally Tirril Harris, George Brown and colleagues aspired to examine the link between social class and depression. The title The Social Origins of Depression signalled that intention. ${ }^{4}$ However, on grounds of methodological pragmatism it became celebrated mainly as a study of female depression; women were more available to participate and so only they were interviewed. Accordingly, the subtitle of the book became A Study of Psychiatric Disorder in Women. Brown and Harris considered that their work demonstrated the exposure of working-class women in 'urban industrialised communities' to depressioninducing stressors, which reflected social inequalities and a 'major social injustice'.

What the study brought to light were the biopsychosocial dimensions expected within the Meyerian legacy, in which the team developed a model of depression that included three groups of aetiological factors. These referred to biographical vulnerability, provoking agents and symptom formation factors. Subsequently, the model was elaborated to include more on childhood adversity and social defeat (negative 'life events') and a breakdown in the interpersonal bonds that sustain a confident sense of self. Brown and colleagues concluded that the probability of depression increases not necessarily with loss or threatened loss per se but with the coexistence of humiliation and entrapment and the meanings that they incur for incipient patients. ${ }^{5}$

The research started an interest in adverse childhood events, which we now know increase the possibility of mental health problems in general and are not diagnosis- 
specific. Around a third of the women studied by the research team had experienced neglect or physical or sexual abuse during childhood. This subgroup had twice the chances of becoming depressed in one year, compared to those without such adverse antecedents, ${ }^{6}$ which also predicted anxiety symptoms. Bifulco and colleagues' work elaborated the original model to mark a convergence with attachment theory, ${ }^{7}$ setting the scene for a 'trauma-informed' approach to mental health work.

The Harris, Brown and colleagues research was augmented in Camberwell by psychiatrists, but this focused on the follow-up of discharged hospital patients with a diagnosis of unipolar depression. ${ }^{8}$ This time, men were included in the sample but were still in a minority. This team concluded that gender, not class, does predict depression and that life events were important. This project was different from the community surveys of the Harris and Brown group, as its focus was on a particular clinical population and their families, with a view to disaggregating the salience of nature and nurture.

This research group embodied equivocation within British psychiatry about 'the social', as the search for the salient role of biogenetics continued as part of the work. This can be contrasted, for example, with the work of Brown and colleagues or that of Goldberg and Huxley, who were more interested in how social factors, as immediate stressors, may impact on somatic systems. ${ }^{9}$ The sampling and theoretical differences in these studies raised questions about the sociological competence on the part of psychiatrists. As will be clear now, their engagement of the 'sociological imagination' was sparse but not always absent. ${ }^{10}$ For reasons of space, our summary of the topic is guided by examples given from British contributions to the main international social psychiatric journal, Social Psychiatry and Social Epidemiology. This brings us to consider how 'the social' was framed and represented in papers from British psychiatry.

\section{British Articles in Social Psychiatry and Social Epidemiology}

When we looked at the articles from the UK in the journal Social Psychiatry and Social Epidemiology (which began life in 1966 as Social Psychiatry), we traced three overlapping framings of 'the social', which for heuristic convenience here we have called 'the micro', 'the meso' and 'the macro'. We provide illustrative examples of this tracing exercise in what follows.

\section{The Micro Version of 'the Social': The Biological Undertow and Clinical Focus}

Adelstein and colleagues reported an epidemiological study from Salford, which described the clinical characteristics of newly diagnosed patients. ${ }^{11} \mathrm{~A}$ series of correlates were reported about sex, class, age and marital status. The authors opted to compare 'functional' mental disorders to Huntington's chorea, noting that the 'resemblance is great, and these data therefore provoke serious consideration of the existence of genetic susceptibility to schizophrenia and psychoneurosis, although there are good reasons for seeking multiple causes including social causes'.

Social psychiatric research set in that period remained wedded to the hospital as an institution, reflected in the reliance and focus on the use of service-based data (rather than community, nonclinical samples) to map out mental disorders in society. Cooper argued for the 'need to look outside hospital' to primary care. ${ }^{12} \mathrm{He}$ identified that women were overrepresented in the latter but not the former, but no sociological hypothesis was raised about 
its reason (e.g. about risky male conduct requiring control). The author did note, however, that more research was required on 'the general population'.

Later, this focus on individual characteristics in clinical samples began to define 'the social', as an outcrop of patient pathology or deficit. For example, Platt and colleagues reported on the development of the 'Social Behaviour Assessment Schedule', to measure 'the patient's disturbed behaviour, the patient's social performance, and the adverse effects on the household'. ${ }^{13}$ Another example of making 'the social' a patient characteristic was the investigation of the problematic conduct of those abusing alcohol in Scotland. ${ }^{14}$

\section{The Meso Level of 'the Social': The Focus on Immediate Relationships}

The reporting of social disability as a product of patient pathology continued but overtime was now augmented by an interest in family life. As we noted earlier, one motive for this was to test the nature/nurture question. The role of family life in relapse but not causation (eschewing a possible implication of British 'anti-psychiatry') came to the fore in the study of 'expressed emotion'. ${ }^{15}$ Speculating more generally about intimacy, Birtchnell and Kennard posed the question, does marital maladjustment lead to mental illness? ${ }^{16}$

The interpersonal field was reflected in the emerging epidemiological picture of the overrepresentation of black and ethnic minority patients (mainly African-Caribbean). Family and cultural features of these groups became a focus of interest, along with a consideration about stressors linked to migration and community; not just clinical samples were investigated. ${ }^{17}$

Up until the mid-1990s the social 'deficits' assumed to be flowing from mental illness continued to be of interest, ${ }^{18}$ as well as an exploration of the racialised picture of admissions, with a particular interest in why rates of psychosis were higher in second generation AfroCaribbean people. ${ }^{19}$ Also, the biogenetic assumption from the 1960 s persevered in studies looking at social factors. ${ }^{20}$

With that continued assumption, premorbid deficits implied an endogenous source for current social disability. An example of the continuing biological undertow was the suggestion that immigrant mental illness might be caused by a virus in their host country. This preference for a putative biological cause is noteworthy given the clear prevalence of both poverty and racism in society.

An alternative exploration of significant others was offered by Morley and colleagues, ${ }^{21}$ who suggested that the relatives of patients are wary of services and this shapes admission decisions of African-Caribbean patients. Also, the continuation of the research on how 'high expressed emotion' in the families of psychotic patients contributed to relapse continued; the relapse focus thereby allowed the biogenetic assumption to be retained. ${ }^{22}$

There was a continuing focus on clinical routines. For example, Tunnicliffe and colleagues were interested in tracing how ethnic background predicted compliance levels with depot medication. ${ }^{23}$ 'The social' then was a profession-centred resource in the research and not a window into sociological understanding. For example, the depot question could have been discussed in terms of psychiatrists as being agents of social control in open settings, in anticipation of the controversy about Community Treatment Orders (see also Chapter 8).

The discursive picture in this period of social psychiatric research is one in which patient characteristics (i.e. symptoms and deficits, with embedding biogenetic assumptions) and service utilisation processes define what is meant by 'the social'. The latter might be extended to family context, as a source of relapse and possible gene pool of aetiology. The 
Camberwell Depression study mentioned in the section 'The Social Origins of Depression' was of this type.

\section{The Macro Level of 'the Social': A Shift Back to Social Causation}

The insights of the ecological wing of the Chicago School of sociology were seemingly unrecognised or acknowledged in the abovementioned published research. However, gradually a fuller account of social causation emerged, along with more methodological sophistication and some willingness to explore the sociological imagination. The latter dawning was evident in a paper by Rodgers looking at the social distribution of neurotic symptoms in the population. ${ }^{24}$ The role of poverty became evident and the author commented (we assume without irony) that previous studies 'may have underestimated the importance of financial circumstances'. Similarly, Gupta showed significant statistical correlations between mental disorder, occupation and urbanicity. ${ }^{25}$ The powerful causal combination of poverty and city living was now being re-vindicated.

Those signs in the 1990s of a recognition of the macro level have been more evident recently. For example, resonating in part with the sociological notion of intersectional disadvantage, the older pattern of racialised admissions was now revisited with the added question of class. Brugha and colleagues found that 'ethnic grouping was strongly associated with: unemployment; lone parent status; lower social class; low perceived social support; poverty (indicated by lack of car ownership) and having a primary social support group of less than three close others'. ${ }^{26}$

By the turn of this century, the taken-for-granted diagnostic categories used by social psychiatrists were subject to critical questioning. The weak construct validity of schizophrenia was conceded and a broader notion of psychosis as the medical codification of madness (i.e. socially unintelligible conduct) emerged. ${ }^{27}$ This marked a recognition that social constructivist arguments might now be relevant to explore, when and if dubious diagnostic concepts were the dependent variable in epidemiology (i.e. what exactly was being studied?). This small shift should not be over-drawn, though; except for querying 'schizophrenia', there was no apparent rush to abandon psychiatric diagnosis in social psychiatric research.

Samele and colleagues found that occupational (but not educational) status predicted psychotic symptoms. ${ }^{28}$ In line with these newer macro-focused studies, Mallett and colleagues found that 'unemployment and early separation from both parents distinguish African-Caribbeans diagnosed with schizophrenia from their counterparts of other ethnic groups as well as their normal peers, and imply that more attention needs to be focussed on socio-environmental variables in schizophrenia research'. ${ }^{29}$ A similar point was made by Marwaha and Johnson about the role of employment in recovery from psychosis. ${ }^{30}$ The focus on black and minority ethnic (BME) patients remained present in the literature but within that there was a return to a focus on the impact of migration, ${ }^{31}$ though with a continuing interest in British-born BME groups as well. ${ }^{32}$

By the start of the present century, there had also been a return to community-based rather than clinical sampling. For example, King and colleagues examined psychotic symptoms in the BME general population and concluded that prevalence rates 'were higher in people from ethnic minorities, but were not consistent with the much higher first contact rates for psychotic disorder reported previously, particularly in Black Caribbeans' ${ }^{33}$ This return to the general population rather than clinical samples also applied to depressive and 
anxiety symptoms, with links being made explicitly to them being inflected by social inequality. ${ }^{34}$

During the first decade of this century there was a continuing service-centred concern but now it was explicitly in relation to the context of deinstitutionalisation, especially when substance misuse amplified the risky conduct of psychotic patients in the community. ${ }^{35}$ Other new trends included a small shift to well-being rather than mental disorder, ${ }^{36}$ as well as a concern with self-harm and suicide, especially in relation to middle-class groups. ${ }^{37}$

\section{Discussion}

We noted that the sociological work of Tirril Harris, George Brown and colleagues was of a different character to that led by psychiatrists, as it was explicitly about social inequality and its implied social injustice (defying the fact-value separation of the positivist tradition). During the 1960s, British social psychiatrists at first tended to discuss 'the social' as an attribute of patients to be measured, taking it for granted that their illness made them socially impaired and that this placed a social burden on others. This gave way to one in which family determinants, especially about relapse or service contact, took on a greater salience. These micro and meso depictions of 'the social' always carried with them the strong presumption of bio-determinism. Eventually, there was a return to a macro-social interest; socio-economic conditions were now causally relevant and community, not clinical, samples regained their importance.

Looking at the literature of the period of interest, apart from this pattern about the framing of 'the social', another observation is the uneven ecology of the research itself. Most of the work is derived from the Institute of Psychiatry in London, augmented by a minority of studies from Scotland and the English provinces. Accordingly, one immediately convenient locality (Camberwell) has been investigated disproportionately. It may well be that Camberwell reflected the UK-wide picture of what was being researched in the past few decades, but we will never know. The dominance of the work in South London may have had the effect of marginalising the impact of attachment theory from the rival Tavistock Clinic, north of the Thames; ${ }^{38}$ and within the London-based quantitative research, the relevant correlations were derived from varying sample sizes. For example, the clinical sample in the Camberwell Depression study in the 1980s was of 130 patients, whereas the community sample from King and colleagues in 2005 was of 4,281 face-to-face interviews.

By the turn of this century, British social psychiatric research was still largely medically led, although the faltering integration of health and social care prompted some social worker leadership. ${ }^{39}$ We also noted some work on assessment tools that was led occasionally by psychologists (e.g. Slade and Kuipers) or sociologists (e.g. Platt). Epistemologically, medical dominance extended to the ongoing reliance on diagnostic groups as dependent variables. However, we noted a cautious shift, for some, from 'schizophrenia' to 'psychosis'. This ambivalence within social psychiatry about reifying diagnoses is an old trope, traceable to Meyerian psychiatry.

At the start of the chapter, we noted that it had provided the basis for a potential collaboration between the psychiatric profession and sociology. The material covered suggests that the latter has not had a consistent impact on the former, with the sociological imagination being in poor supply at times, though occasionally contributions from sociologists were evident. ${ }^{40}$ We mention this separation because sociologists themselves have produced their own research on mental health and illness, which does cite the psychiatric 
(and psychological) literature. We have summarised this intermittently in the past thirty years.

\section{Conclusion}

British social psychiatry has tended to start with the anchor point of clinical concerns and diagnoses and their presupposed underlying biological causation. It then moves out tentatively to interpersonal settings and societal stressors. By contrast, sociologists are more likely to start at the other end of the telescope. Their focus is on groups of people in their social context not pathology, which then comes into focus because of sociological reflection more widely. Their alternative agenda inter alia includes medical dominance and the social control role of psychiatry in society, eugenics, political economy, lay views, especially from service users, and metaphysical debates about social causationism and social constructivism. A life-course approach predominates, for example, with considerations about childhood adversity and mental health in old age. These topics, drawing upon wider sociological work, might have helped social psychiatrists to develop their sociological imagination.

No discipline has a monopoly of understanding about this topic and so the interdisciplinary potential of social psychiatry, broadly conceived, remains an opportunity for all. However, for its potential to be realised, interdisciplinarity needs to be fully respected by all. The shortcomings about the sociological imagination, which we drew attention to in this chapter, might have been avoided had this point been recognised in the mid-1960s in British social psychiatry. Psychiatric wariness of sociology was one likely source of this shortcoming, along with the self-referential norm in the medical literature reinforcing a uni-disciplinary silo.

\section{Key Summary Points}

- Either side of the Second World War, social psychiatry had emerged in the United States, influenced by Adolf Meyer's work, the ecological wing of the Chicago School of sociology and, subsequently, the development of the biopsychosocial model by George Engel. The sociological imagination in British social psychiatry was sparse but not always absent.

- Most of the work in UK is derived from the Institute of Psychiatry in London, augmented by a minority of studies from Scotland and the English provinces.

- By the turn of the present century, the taken-for-granted diagnostic categories used by social psychiatrists were subject to critical questioning. The weak construct validity of schizophrenia was conceded and a broader notion of psychosis as the medical codification of madness (i.e. socially unintelligible conduct) emerged.

- No discipline has a monopoly of understanding about this topic and so the interdisciplinary potential of social psychiatry, broadly conceived, remains an opportunity for all. However, for its potential to be realised, the principle of interdisciplinarity needs to be fully respected by all. British psychiatry has been wary of sociology and has had a tendency, like other medical specialities, to be self-referential in its published outputs, thereby producing a largely uni-disciplinary silo.

\section{Notes}

1. D. Pilgrim and A. Rogers, The troubled relationship between psychiatry and sociology. International Journal of Social Psychiatry (2005) 51: 228-41. 
2. T. Main, The hospital as a therapeutic institution. Bulletin of the Menninger Clinic (1946) 10: 64-71; M. Jones, The treatment of personality disorders in a therapeutic community. Psychiatry (1957) 20: 211-20; J. Bowlby, Maternal Care and Mental Health. Geneva: World Health Organization, 1951; D. Goldberg and P. Huxley, Common Mental Disorders: A Bio-social Model. London: Tavistock and Routledge, 1992.

3. G. Engel, The clinical application of the biopsychosocial model. American Journal of Psychiatry (1980) 137: 535-44.

4. G. W. Brown and T. O. Harris, The Social Origins of Depression: A Study of Psychiatric Disorder in Women. London: Tavistock, 1978.

5. G. W. Brown, T. O. Harris and C. Hepworth, Loss, humiliation and entrapment among women developing depression: A patient and non-patient comparison. Psychological Medicine (1995) 25: 7-21.

6. A. Bifulco, T. O. Harris and G. W. Brown, Mourning or inadequate care? Reexamining the relationship of maternal loss in childhood with adult depression and anxiety. Development and Psychopathology (1992) 4: 119-28.

7. A. Bifulco, P. M. Moran, P. Ball et al., Adult attachment style. I: Its relationship to clinical depression. Social Psychiatry and Psychiatric Epidemiology (2002) 37: 50-9.

8. P. Bebbincton, T. Brugha, T. B. McCarthy et al., The Camberwell Collaborative Depression Study - I: Depressed probands: Adversity and the form of depression. British Journal of Psychiatry (1988) 152: 754-65; P. McGuffin and P. Bebbington, The Camberwell collaborative depression study - II: Investigation of family members. British Journal of Psychiatry (1988): 766-74; P. McGuffin, R. Katz and P. Bebbington, The Camberwell collaborative depression study - III: Depression and adversity in the relatives of depressed probands British Journal of Psychiatry (1988) 152: 775-82.

9. Goldberg and Huxley, Common Mental Disorders.

10. C. W. Mills, The Sociological Imagination. New York: Oxford University Press, 1959.

11. A. M. Adelstein, M. Downham, Z. Stein et al., The epidemiology of mental illness in an English city: Inceptions recognized by Salford psychiatric services. Social Psychiatry and Psychiatric Epidemiology (1968) 3: $47-9$.

12. B. Cooper, Psychiatric disorder in hospital and general practice. Social Psychiatry (1966) 1: 7-10.

13. S. Platt, A. Weyman, S. Hirsch et al., The Social Behaviour Assessment Schedule (SBAS): Rationale, contents, scoring and reliability of a new interview schedule. Social Psychiatry and Psychiatric Epidemiology (1980) 15: 43-55.

14. M. A. Plant and F. Pirie, Self-reported alcohol consumption and alcohol-related problems: A study in four Scottish towns. Social Psychiatry and Psychiatric Epidemiology (1979) 14: 65-73.

15. L. Kuipers Expressed emotion in 1991. Social Psychiatry and Psychiatric Epidemiology (1992) 27: 1-3.

16. J. Birtchnell and J. Kennard, Does marital maladjustment lead to mental illness? Social Psychiatry and Psychiatric Epidemiology (1983) 18: 79-88.

17. E. Hurry, P. Sturt, P. Bebbington and C. Tennant, Socio-demographic associations with social disablement in a community sample. Social Psychiatry and Psychiatric Epidemiology (1983) 18: 3113-21.

18. T. S. Brugha, J. Wing and J. C. Brewin, The relationship of social network deficits in social functioning in long term psychiatric disorders. Social Psychiatry and Psychiatric Epidemiology (1993) 28: 218-24.

19. D. McGovern and R. Cope, First psychiatric admission rates of first and second generation Afro Caribbeans. Social Psychiatry and Psychiatric Epidemiology (1987) 22: 139-49; D. McGovern and R. Cope, Second generation Afro-Caribbeans and young whites with a first admission diagnosis of schizophrenia. Social Psychiatry and Psychiatric Epidemiology (1991) 26: 95-9.

20. R. Mallett, J. Leff, D. Bhugra et al., Social environment, ethnicity and schizophrenia. Social Psychiatry and Psychiatric Epidemiology (2002) 37: 229-335.

21. R. Morley, T. Wykes and B. MacCarthy, Attitudes of relatives of Afro-Caribbean patients: Do they affect admission? Social Psychiatry and Psychiatric Epidemiology (1991) 26(1): 87-193. 
22. R. G. McCreadie, The Nithsdale schizophrenia surveys. Social Psychiatry and Psychiatric Epidemiology (1992) 27: $40-5$.

23. S. Tunnicliffe, G. Harrison and P. J. Standen, Factors affecting compliance with depot injection treatment in the community. Social Psychiatry and Psychiatric Epidemiology (1992) 27: 230-3.

24. B. Rodgers, Socio-economic status, employment and neurosis. Social Psychiatry and Psychiatric Epidemiology (1991) 26: 104-14.

25. S. Gupta, Can environmental factors explain the epidemiology of schizophrenia in immigrant groups? Social Psychiatry and Psychiatric Epidemiology (1993) 28: 263-6.

26. T. S. Brugha, R. Jenkins, P. Bebbington et al., Risk factors and the prevalence of neurosis and psychosis in ethnic groups in Great Britain. Social Psychiatry and Psychiatric Epidemiology (2004) 39: 939-46.

27. J. Van Os, P. Jones, P. Sham et al., Risk factors for onset and persistence of psychosis. Social Psychiatry and Psychiatric Epidemiology (1998) 33: 596-605.

28. C. Samele, J. van Os, K. McKenzie et al., Does socioeconomic status predict course and outcome in patients with psychosis? Social Psychiatry and Psychiatric Epidemiology (2001) 36: 573-81.

29. S. Marwaha and S. Johnson, Schizophrenia and employment: A review. Social Psychiatry and Psychiatric Epidemiology (2004) 39: 337-49.

30. G. Leavey, K. Hollins, M. King et al., Psychological disorder amongst refugee and migrant schoolchildren in London. Social Psychiatry and Psychiatric Epidemiology (2004) 39: 191-5.

31. S. Pantelidou and T. Craig, Culture shock and social support. Social Psychiatry and Psychiatric Epidemiology (2006) 41: 777-781; R. Gater, B. Tomenson, C. Percival et al., Persistent depressive disorders and social stress in people of Pakistani origin and white Europeans in UK. Social Psychiatry and Psychiatric Epidemiology (2008) 44: 198-209.

32. E.g. M. King, J. Nazroo, J. S. Weich et al., Psychotic symptoms in the general population of England. Social Psychiatry and Psychiatric Epidemiology (2005) 40: 375-81.

33. D. Melzer, D.T. Fryers, R. Jenkins et al., Social position and the common mental disorders with disability. Social Psychiatry and Psychiatric Epidemiology (2003) 38: 238-43.

34. J. Todd, G. Green, M. Harrison et al., Social exclusion in clients with comorbid mental health and substance misuse problems. Social Psychiatry and Psychiatric Epidemiology (2004) 53: 519-87.

35. M. J. Maynard, S., Harding and H. Minnis, Psychological well-being in Black Caribbean, Black African, and White adolescents in the UK Medical Research Council DASH study. Social Psychiatry and Psychiatric Epidemiology (2007) 42: 759-69.

36. I. Collins and E. Paykel, Suicide amongst Cambridge University Students 1970-1996. Social Psychiatry and Psychiatric Epidemiology (2000) 35: 128-32.

37. D. J. Bartram, G. Yadegarfar and D. S. Baldwin, A cross-sectional study of mental health and well-being and their associations in the UK veterinary profession. Social Psychiatry and Psychiatric Epidemiology (2009) 44: 1075-85; P. Huxley, S. Reilly, E. Robinshaw et al., Interventions and outcomes of health and social care service provision for people with severe mental illness in England. Social Psychiatry and Psychiatric Epidemiology (2003) 38: 44-8.

38. Cf. Bifulco, Moran, Ball et al., Adult attachment style. I: Its relationship to clinical depression.

39. J. Nazroo, Y. Kamaldeep, S. Bhui et al., Where next for understanding race/ethnic inequalities in severe mental illness? Structural, interpersonal and institutional racism. Sociology of Health and Illness (2020) 42: 262-76.

40. A. Rogers and D. Pilgrim, A Sociology of Mental Health and Illness (6th ed.). Maidenhead: Open University Press, 2020. 